\title{
Homeopatia e alopatia em disputa no início do século XX
}

\author{
Homeopathy and allopathy in dispute at the \\ beginning of the twentieth century
}

\author{
Marilane Machado \\ Doutoranda, Programa de Pós-graduação em História/Universidade Federal do Paraná. \\ marilanemac@ig.com.br
}

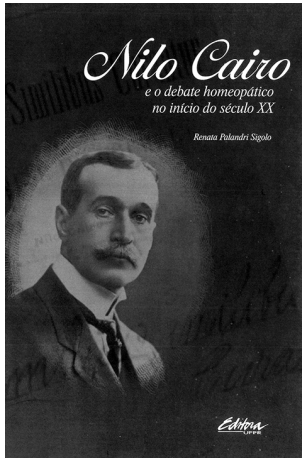

SIGOLO, Renata Palandri. Nilo Cairo e o debate homeopático no início do século XX. Curitiba: Editora UFPR. 2012. 254p.

R esultado de pesquisa que deu origem inicialmente a uma tese de Rdoutoramento em história na Universidade Federal do Paraná, a obra Nilo Cairo e o debate homeopático no início do século $X X$ foi publicada pela Editora da Universidade Federal do Paraná em 2012 como edição comemorativa dos cem anos daquela universidade.

A autora, Renata Palandri Sigolo, concluiu seu doutorado em 1999. Desde 1996 é professora do Departamento de História da Universidade Federal de Santa Catarina. Sua trajetória acadêmica é marcada por estudos envolvendo temáticas como história da saúde e do bem-estar, discurso médico, representações sociais e medicinas alternativas.

Nilo Cairo foi um médico paranaense, nascido em 12 de novembro de 1874 em Paranaguá. É conhecido por ser um dos fundadores da Universidade do Paraná em 1912. Participou ativamente do debate homeopático, tanto no Rio de Janeiro quanto em Curitiba. Em 1903 elaborou sua tese inaugural na Faculdade de Medicina do Rio de Janeiro, Similia similimum curantur, sua primeira obra sobre medicina homeopática. A tese foi rejeitada pela academia, e Nilo Cairo escreveu O pé equino, em 1904, para conclusão do curso de medicina. Exerceu intensa atividade profissional, participando dos debates sobre as teorias médicas da época. Autor de vários artigos na imprensa homeopática e alopática e também na imprensa leiga, foi redator dos Anais do Instituto Hahnemanniano do Brasil - principal instituição da homeopatia do Brasil - e também da Revista Homeopática do Paraná, que transformou em Revista Homeopática Brasileira.

A publicação dessa obra possibilitou um olhar diferenciado sobre a criação da Universidade do Paraná e sobre o doutor Nilo Cairo da Silva, cuja memória foi construída em torno de sua participação na fundação da universidade. A autora visou analisar sua atuação como médico homeopata e compreender o debate médico nacional do início do século XX no qual esteve inserido. Para isso levou em conta que o surgimento da Universidade do Paraná, em especial da Faculdade de Medicina, fez parte de contexto mais amplo, que envolveu a luta da 
homeopatia para ser reconhecida como ciência, bem como a busca de hegemonia da alopatia em maio ao espaço acadêmico. A principal problemática do trabalho é compreender a história da homeopatia como um processo de luta por sua legitimação enquanto saber médico no início do século XX, pela atuação do médico homeopata.

A delimitação temporal da pesquisa é entre 1903, ano em que Nilo Cairo elaborou sua primeira tese para a Faculdade de Medicina do Rio de Janeiro, e 1914, ano em que ele inseriu matérias relacionadas à homeopatia nos cursos de farmácia e medicina da Faculdade de Medicina da recém-inaugurada Universidade do Paraná, disciplinas previstas, mas não lecionadas. Dentro desse recorte temporal, a autora fez uma verdadeira garimpagem em periódicos médicos alopatas e homeopatas, periódicos leigos e outras publicações médicas como almanaques, em busca de discursos publicados por Nilo Cairo e por seus interlocutores no contexto de disputas simbólicas na qual homeopatas buscavam a legitimação da medicina homeopática como verdadeiro saber médico científico e alopatas buscavam a deslegitimação desse saber.

No primeiro capítulo, "Hahnemann e Comte nos jardins de Hipócrates", a autora inicia a narrativa a partir da formatura de Nilo Cairo na Faculdade de Medicina do Rio de Janeiro. Levanta como fator de sua distinção perante outros colegas sua idade e a experiência de vida que já havia acumulado. Em 1904, ano de término do curso de medicina, contava 30 anos de idade e já havia obtido o título de bacharel em ciências físicas e matemáticas na Escola Militar. A autora relata a reprovação da primeira tese de Nilo Cairo e a escrita da segunda, que lhe permitiu a formatura.

A partir daí descreve os princípios básicos da teoria hahnemanniana, segundo o discurso dos médicos homeopatas do período, apresenta os conceitos de força vital, saúde, doença e terapêutica e demonstra como os homeopatas buscavam sua aproximação com a teoria positivista, visando atender às necessidades de legitimação da homeopatia.

Para a escrita desse capítulo as fontes utilizadas foram artigos publicados nos Anais de Medicina Homeopática, órgão veiculador de ideias do Instituto Hahnemanniano do Brasil; na Revista Homeopatica do Paraná, fundada por Nilo Cairo em 1906, sendo que em 1908 sua circulação foi ampliada, quando se transformou na Revista Homeopática Brasileira, além de obras e teses de homeopatas, como a tese inaugural de Nilo Cairo.

No capítulo segundo, "A homeopatia no 'Século dos Micróbios'”, são apresentadas as principais teorias defendidas pela medicina alopata no período: a dos miasmas, a dos humores e a microbiologia. A autora trata dos conflitos do discurso homeopático com o alopático a partir das publicações em periódicos. Dedica parte do capítulo à análise do que considera estratégias discursivas no contexto das discussões em torno da obrigatoriedade da vacinação antivariólica, quando a maior parte dos homeopatas colocou-se a favor do método terapêutico da vacinação, pois o princípio da vacinação estaria de acordo com a teoria homeopática de que o semelhante se cura através do semelhante, mas contra sua obrigatoriedade, pois os ideais positivistas, dos quais eram adeptos, defendiam o princípio de liberdade.

Para a redação desse capítulo a autora realizou pesquisas em periódicos de ambas as vertentes médicas: Anais de Medicina Homeopática, Revista Homeopática do Paraná e Revista Homeopática Brasileira; Brasil-Médico (periódico médico oficial do Rio de Janeiro), em que 
encontrou críticas de alopatas endereçadas aos homeopatas; e Jornal do Comércio, do Rio de Janeiro, utilizado na abordagem sobre a vacinação obrigatória de 1904.

No terceiro capítulo, "A conquista do público", Sigolo se dedicou aos discursos produzidos pelos homeopatas tendo como destinatário o público leigo. No desejado processo de transformação da homeopatia em medicina científica era importante obter o reconhecimento dos leigos, que proporcionaria a legitimação necessária. A autora demonstrou algumas estratégias discursivas para a conquista desse público, como, por exemplo, relatos de "conversões" de médicos alopatas à homeopatia e propagandas de obras homeopáticas, como guias, manuais e folhetos.

As fontes documentais em que esses discursos podem ser encontrados são os periódicos leigos, que atingiam o grande público. Foram consultados o Correio Paulistano, de São Paulo; o Jornal do Comércio, do Rio de Janeiro e o Diário da Tarde, de Curitiba, o último, local privilegiado dos discursos de Nilo Cairo. Além desses, também foram utilizados os periódicos homeopáticos citados, bem como as revistas alopáticas, como a Revista Médico-Cirúrgica do Brasil, do Rio de Janeiro, e a Gazeta Clínica, de São Paulo.

Por fim, no quarto capítulo, intitulado "Ensinando a Similia similibus curantur", a autora buscou nos periódicos já citados, além do Diário da Tarde, nos relatórios e estatutos da Universidade do Paraná e em algumas obras de Nilo Cairo, acompanhar os debates em torno da legitimação de "porta-vozes" da medicina homeopática. Demonstrou a vontade e o empenho de Nilo Cairo e de alguns de seus companheiros em fundar uma pequena escola de medicina homeopática à sombra do Instituto Hahnemanniano do Brasil, por acreditar que mais do que os debates públicos com os alopatas, a formação de médicos em escolas homeopatas traria o estatuto de ciência reivindicado pela homeopatia. Esse foi, no entanto, um empreendimento frustrado pela falta de apoio político e talvez o fator determinante para que Nilo Cairo retornasse ao Paraná em 1911, quando se mudou do Rio de Janeiro para Curitiba e apresentou sua carta de demissão ao Instituto Hahnemanniano do Brasil.

A autora deu especial atenção ao período entre 1911 e 1914, quando se deram debates em torno do ensino da teoria hahnemanniana e das exigências para admissão nos quadros do Instituto Hahnemanniano do Brasil no contexto de alteração de estatutos, em 1912, ocasião em que houve forte reação de Nilo Cairo contra as alterações empreendidas, através das quais passaria a ser permitida a admissão no Instituto de pessoas sem o título médico.

Neste contexto se deu a fundação da Universidade Federal do Paraná, em 1912, e no ano seguinte foi criado o curso de medicina da instituição. Um de seus idealizadores e fundadores foi Nilo Cairo, que expressou a necessidade do ensino da medicina homeopática na universidade recém-criada e incorporou a seu currículo disciplinas da área homeopática, que, no entanto, logo foram eliminadas.

A obra traz uma pluralidade de contribuições importantes para a área de história. Aos que se dedicam aos estudos de história da saúde, as disputas simbólicas e discursivas envolvendo o saber médico e homeopático no início do século XX são abordadas de maneira aprofundada. É também uma contribuição interessante aos que se voltam para os estudos biográficos na história, pois toda a pesquisa empreendida pela autora se dá em torno da busca de discursos envolvendo um personagem, Nilo Cairo; seus discursos publicados em periódicos são o fio condutor da pesquisa, e a partir deles a autora consegue traçar um panorama de suas redes 
de relações, no que diz respeito aos debates entre defensores da medicina homeopática e da alopática no início do século XX. Por fim, questões metodológicas da pesquisa em periódicos podem ser apreendidas pelos que têm nos jornais e revistas suas principais fontes de acesso ao conhecimento histórico. 